\title{
Hydrophilic Modified clay Nanocomposites: Effect of clay on Thermal and Vibrational Properties
}

\author{
A. Kishore ${ }^{1}$, D. B. Venkatesh ${ }^{1}$, M. Ashok Kumar ${ }^{2, *}$, A. Ramesh ${ }^{2}$, \\ K. Nikil Murthy ${ }^{3}$, N. Karthikeyan ${ }^{4}$ \\ ${ }^{1}$ Vardhaman College of Engineering, Kacharam - Village, Shamshabad, \\ Ranagareddy - Dist 501218, India \\ ${ }^{2}$ Department of Mechanical Engineering GATES Institute of Technology, Gooty, \\ Anantapur - 515401, Andhra Pradesh, India \\ *Telephone: (+91) 9441115859 \\ ${ }^{3}$ Department of Mechanical Engineering, Brilliant Grammar School Educational Society's Group of \\ Institutions Engineering and Phamacy, Abdullapur Village, Hyderabad, Ranga Reddy District, India \\ ${ }^{4}$ Kasireddy Narayan Reddy, College of Engineering and Research, Abdullapur Village, \\ Ranga Reddy District, India \\ *E-mail address: ashokkumarmala7@gmail.com
}

\begin{abstract}
Epoxy (LY-556/HY-951) system filled with modified clay (MC) was synthesized by using mechanical shear mixing with the addition of hardener as tri-ethylene-tetra-amine (TETA). The effect of the fumed silica can be negated by the application of a shear force (e.g. mixing, brushing, spraying etc), allowing the liquid to flow, level out and permit the escape of entrapped air. The reinforcement effects of MC in the epoxy polymer on thermal, mechanical and vibration properties were studied. Curing study shows that the addition MC does not show any effect in the curing behavior of epoxy polymer. Thermogravimetry analysis (TGA) shows enhanced thermal stability for epoxy with MC fillers. The epoxy with MC fillers shows considerable improvement on tensile and impact properties over pure epoxy polymer. SEM studies shows that addition of clay significantly turns the epoxy system from brittle to ductile nature was played instrumental in scaling performance. The improvement in tensile and impact properties of nanocomposites is supported with the fracture surface studies. Epoxy with MC fillers shows enhanced vibration characteristics than that of the pure epoxy polymer. FTIR studies indicated the formation of $\mathrm{C}-\mathrm{H}$ bonds on the surface of the nanocomposites.
\end{abstract}

Keywords: Hydrophilic nanoclay; Epoxy Nanocomposites; Mechanical properties

\section{INTRODUCTION}

The epoxy polymers used as adhesives and as the matrices of composite materials are amorphous and highly crosslinked thermosetting materials. These chemical structures result in many useful properties such as a high modulus and failure strength, low creep and good performance at elevated temperatures. However, this chemical structure also leads to one highly undesirable property in that they are relatively brittle materials, with a poor resistance 
to crack initiation and growth. The authors have previously shown that nanocomposites may be successfully manufactured using $20 \mathrm{~nm}$ diameter silica nanoparticles, and that these particles increase the toughness of the material. Siegel et al. [1] obtained an increase of $15 \%$ of the strain to failure filling an epoxy resin with $10 \mathrm{wt} . \%$ of nanometric $\mathrm{TiO}_{2}$ particles. Evora et al. [2] found that adding only 1 vol. $\%$ of $\mathrm{TiO}_{2}$ nanoparticles within unsaturated polyester resin increased the fracture toughness of about $57 \%$ was due to the uniform and fine dispersion of the filler within the resin at low volume contents. More significant enhancements in fracture toughness (almost $100 \%$ at 4.5 vol. $\%$ of $\mathrm{Al}_{2} \mathrm{O}_{3}$ nanoparticles in unsaturated polyester) were achieved improving the particle-matrix adhesion through a silane surface treatment [3]. Wetzel et al. [4] studied the effects of nano (alumina) and microspherical (calcium silicate) particle addition to epoxy resin and found increases in flexural modulus (up to $35 \%$ ), strength (up to $20 \%$ ) and Charpy impact energy (up to $35 \%$ ). In a following, interesting work [5], neat epoxy reinforced with $\mathrm{Al}_{2} \mathrm{O}_{3}$ nanoparticles at different volume contents was investigated. The 10 vol. \% epoxy/ $\mathrm{Al}_{2} \mathrm{O}_{3}$ nanocomposite exhibited significant improvements in flexural modulus (around $40 \%$ ), strength $(15 \%)$ and fracture toughness $(120 \%)$. Furthermore, the crack propagation threshold and resistance turned out to be improved dramatically, with the crack propagation rates for nanocomposites being orders of magnitude slower than neat resin for the same range of SIF. Adebahr et al. [6] proposed a novel route to prepare nanocomposites consisting of monodispersed $\mathrm{SiO}_{2}$ nanoparticles and reactive resin. The addition of $23 \mathrm{wt}$ \% of particles subjected to thermal anhydride curing induced a $66 \%$ increase in $\mathrm{K}_{\mathrm{IC}}$, while UV curing led to an improvement of $82 \%$ at $50 \mathrm{wt} . \%$. Lin et al. [7] reported that tensile and impact strength of titanium dioxide and montmorillonite filled epoxy resin reached a maximum for a filler content of 5-8 vol. \% and decreases at higher filler contents, sometimes even below the neat resin values. Ragosta et al. [8] improved the mechanical properties of epoxy resin adding $10 \mathrm{wt} . \%$ of silica particles with a diameter of $10-15 \mathrm{~nm}$. The normalized elastic modulus reached the value of 1.5 , while the normalized yield strength increased up to 1.3. The addition of silica raised the fracture energy of the epoxy matrix by a factor of about 4 , whereas the increase of $\mathrm{K}_{\mathrm{IC}}$ was twofold. Zheng et al. [9] found that the addition of $3 \mathrm{wt}$ \% of silica nanoparticles within epoxy matrix leads to an increase in tensile strength of $115 \%$, while the impact strength increases by $56 \%$. In the literature, the toughening effect due to the addition of particles to polymers has been studied for a long time [10-12]. Different toughening mechanisms have been mentioned, such as the localized inelastic matrix deformation and void nucleation, particle debonding, crack deflection, crack pinning, crack tip blunting, particle deformation or breaking at the crack tip. However, it is still an open question which is the effective mechanisms responsible for toughening on nanocomposites [13]. Furthermore, experimental techniques and descriptive models are based on macro-mechanical concepts. Thus, their application to nanocomposites is not straightforward and indeed questionable. Particle-matrix debonding and localized deformations in the process zone ahead of the crack tip are probably responsible of the considerable toughening effect brought by nanomodification. Recent experimental investigations by Johnsen et al. on silica nanoparticle reinforced epoxy polymers confirm these assumptions [14]. Because of the very high specific surface area, even very low filler contents can significantly contribute to matrix reinforcement. Especially interface related effects, such as debonding mechanisms and void nucleation could play a significant role even at low volume contents. Although classical mechanical theories concerning particle toughening sometimes even predict a decrease of toughening contribution with decreasing particle size, the increasing amount of interfacial area and absolute number of particles in the process zone can be reasons for the experimentally observed increases in $\mathrm{K}_{\mathrm{IC}}$ [15]. Xie et al. 
[16] reported the improvement of the mechanical properties of PVC with the addition of $\mathrm{CaCO}_{3}$. At 5 vol. \%, optimal performances were achieved in Young's modulus, tensile yield strength, and strain to failure and Charpy impact energy. The filler enabled ductile fracture caused by elevated triaxial stresses at the neck region and consequently debonding at the particle-matrix interface. Increasing the load, the ligaments between the voids were stretched increasing the energy consumption. The unmodified MMT clay addition leads to the conventional composites. The exfoliated structure possesses superior properties among the three existing structures. The high surface contact area of matrix polymer to nanolayers, uniform distribution of nano layers, etc. of exfoliated structure enhance the properties than other two structures [17-20]. Thermoset epoxy-clay nanocomposites (ECN) are studied under different curing conditions, synthetic routes, organoclays, etc. The report suggests that good exfoliation can be achieved in ECN when amine based curing agents are used [21-24].

The main objective of the researcher is to attempt a lighter material which promises to have high performance applications, as nanocomposites form a good platform for generating lighter materials. Although several types of amine curing agents are available in the literature, limited reports are available on TETA curing agent [25-31]. The TETA curing agent is widely used for making glass fibre reinforced epoxy composites. The main purpose of nanoclay filler is to increase the matrix properties of fibre reinforced polymer composites. The addition of nanoclay in epoxy resin with addition of TETA curing agent is an important phenomenon to consider as large amount of glass fibre reinforced composites are used in several applications. In this work, the effect of modified MMT clay when dispersed into the epoxy polymer matrix, under TETA curing is studied. The curing behaviour, structure, tensile, thermal and vibrational, SEM and FTIR properties are studied as a function of clay concentrations.

\section{EXPERIMENTAL DETAILS}

\section{1. Materials}

The matrix material used in this present study is a commercially available epoxy resin (Aradur LY-556) and hardener (TETA, Araldite HY-951) supplied by Huntsman, Switzerland. nano filler was used in this study Montmorillonite clay (Product No: 682659; Brand: Aldrich, Product name: Nanoclay, hydrophilic bentonite; Formula: $\mathrm{H}_{2} \mathrm{Al}_{2} \mathrm{O}_{6} \mathrm{Si}$; Molecular weight: $180.1 \mathrm{~g} / \mathrm{mol}$; Appearance (Color): Conforms to Requirements Light Tan to Brown; Appearance (Form): Powder; Loss on drying: $\leq 18.0 \%$; Density: $600-1100 \mathrm{~kg} / \mathrm{m}^{3}$; Bulk density: Avg. particle size: $\leq 25$ mocron) supplied by Sigma-Aldrich Chemicals Pvt. Limited, Bangalore, India. The surface of the clay was chemically modified with coupling agent as 3-aminopropyltrimethoxysilane. The surface modification processes as well as the manufacturing parameters are reported elsewhere [18].

\section{2. Nanocomposite fabrication}

Initially epoxy resin is heated at $80^{\circ} \mathrm{C}$ for $1 \mathrm{~h}$. Clay was kept in the oven for about half an hour at $50{ }^{\circ} \mathrm{C}$ to keep the moisture at bay. The clay is then gently added in to the resin bath. Mixing of clay and epoxy is carried out by mechanical shear mixer. The mixer rotates at $1000 \mathrm{rpm}$ and mixing is carried out for $2 \mathrm{~h}$. After uniform mixing of clay and resin, TETA hardener is added in to the resin/clay solution. The resin to hardener ratio is maintained 10:1, and then casted in the mold. The mold is kept at $80{ }^{\circ} \mathrm{C}$ for $4 \mathrm{~h}$ until complete polymerization occurs. Hand-lay up technique was used to impregnate the composite structures. The nanocomposite specimens synthesized by this method are tested for various characterizations. 


\section{3. Characterization}

Curing characteristics of epoxy and epoxy filled MC series was studied using DSC. The sample (consisting of resin, clay and hardener prior to curing) of $5 \mathrm{mg}$ is taken in an alumina crucible and heat is applied at the rate of $10{ }^{\circ} \mathrm{C} \mathrm{min}$. Modal analysis is performed to calculate natural frequency and damping factor ' $n$ '. Damping factor is calculated using impulse hammer technique (IHT) and logarithmic decrement method (LDM). Specimens of $250 \mathrm{~mm} \mathrm{x}$ $25 \mathrm{~mm} \times 4 \mathrm{~mm}$ is prepared, in which one end of beam is clamped and other end is attached to accelerometer to obtain vibration modes. Natural frequency is determined by impulse loading at free end of the bean using impulse exicitation (Rion PH 7117, modally tuned hammer). The signal received from accelerometer is displayed in Fast Fourier Transform (FFT), in which natural frequency is noted down for various modes. Damping factor ' $n$ ' using IHT is determined using half power bandwidth method.

The expression for damping factor by half power width technique is given by ( $\left.\xi=\Delta \omega / 2 \omega_{n}\right)$, where $\Delta \omega$ is bandwidth at half-power points of resonant peak for the nth mode and $\omega_{n}$ is resonant frequency. The half power points are found at $1 / \sqrt{2}$ of maximum peak value. In the LDM, sine wave signal is supplied to drive the modal exciter to excite the cantilever beam specimen. During the natural frequency mode, amplitude increases to a large extent, once the resonance is achieved. At this point, the excitation signal is disconnected freely and a typical free decay curve is obtained. From this decay curve, two experimental amplitude data points are collected namely $\mathrm{x}_{1}$ and $\mathrm{x}_{\mathrm{n}+1}$, and the damping factor $\mathrm{n}$ is calculated by using the expression

$$
\begin{aligned}
& \delta=\frac{1}{n+1} \ln \frac{x_{1}}{x_{n+1}} \\
& \xi=\frac{\delta^{2}}{\sqrt{A \pi^{2}+\delta^{2}}}
\end{aligned}
$$

where $\xi$, the damping factor, $\mathrm{n}+1$, the number of cycles, $\delta$ is the logarithmic decrement, $\mathrm{x}_{1}$ and $\mathrm{x}_{\mathrm{n}+1}$ are the two displacement values at the time intervals $t_{1}$ and $t_{2}$, respectively. A Jeol JSM 840A Japan scanning electron microscope (SEM) was used to study the morphology of fractured surfaces of silica/clay nanocomposite samples at different magnifications. The fractured surfaces of tensile test specimens carried out using SEM. Samples were gold-coated initially subjecting it to SEM analysis.

The scanning electron micrograms of different cross-sections of the nanocomposite samples of pure epoxy, filled with fumed silica and clay nanocomposites, are studied. Tensile strength was studied using an universal testing machine (UTM) supplied by Instron Corporation; 3369, series-9 automated testing machine was used with a crosshead speed of 5 $\mathrm{mm} / \mathrm{min}$. Testing samples were prepared in dumb-bell shapes and these dimensions are $100 \mathrm{x}$ $20 \times 3 \mathrm{~mm}^{3}$ based on the ASTM D 638 standards. In each case, five samples were tested and the average value tabulated.

The thermal characteristics of the epoxy/clay/silica nanocomposites were measured using both differential scanning calorimetry (DSC-2010 TA Instrument) and 
thermogravimetric analyses (TGA) at a rate of $10{ }^{\circ} \mathrm{C} / \mathrm{min}$ under nitrogen flow. The FTIR spectra of the powders of the untreated and alkali treated fabric samples were run on an ABBBomem FLATA-2000 model spectrophotometer using $\mathrm{KBr}$ pellets. The concentration of the fabric powder was maintained at $1 \%$ in $\mathrm{KBr}$.

\section{RESULTS AND DISCUSSIONS}

\section{1. Curing characteristics}

The DSC curing charateristics of epoxy and epoxy filled with MC are shown in Fig. 1. It is seen that the addition of MC does not shift the exothermic peak. The result suggests that addition of MC fillers in epoxy resin does not affect the curing of epoxy. The addition of MC fillers in the epoxy decreases the intensity of exothermic peak. The clay addition continuously decreases the exothermic peak and this is due to decrease in concentration of epoxy resin on clay addition. It is stated that the presence of organoions in MC increases the polymerization of epoxy by catalytic effect [21] and has to increase the curing temperature. However, the existence of nanolayers affects the polymerization of epoxy. Results show that the effect of nanolayers restricting the polymerization is more than the polymerization of organoions with epoxy polymer, and hence decreases the curing temperature of epoxy resin.

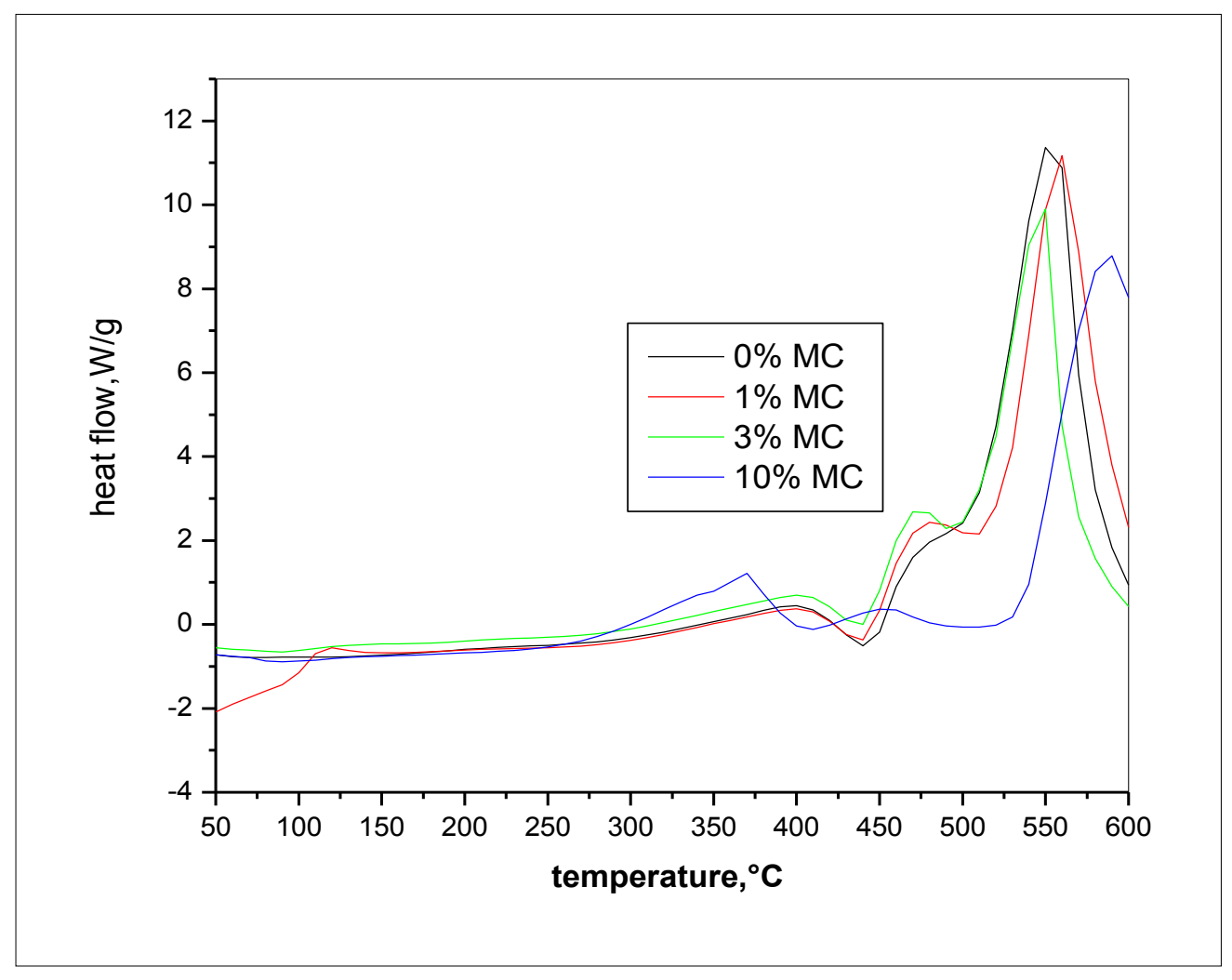

Fig. 1. DSC scans of epoxy with MC series. 


\section{2. Thermogravimetry analysis [TGA]}

Figure 2 shows decomposition of epoxy filled MC particles. The MC shows negligible decomposition up to $600{ }^{\circ} \mathrm{C}$. The addition of $\mathrm{MC}$ particles does not improve the decomposition of epoxy polymer. There is a marginal shift in decomposition temperature when $\mathrm{MC}$ is added in to the epoxy polymer. The improved thermal stability is noticed for epoxy filled MC series at higher temperatures $\left(>400^{\circ} \mathrm{C}\right)$. The reinforcement of MC increases the decomposition of epoxy. The MC addition does not show any improvement in decomposition of epoxy polymer.

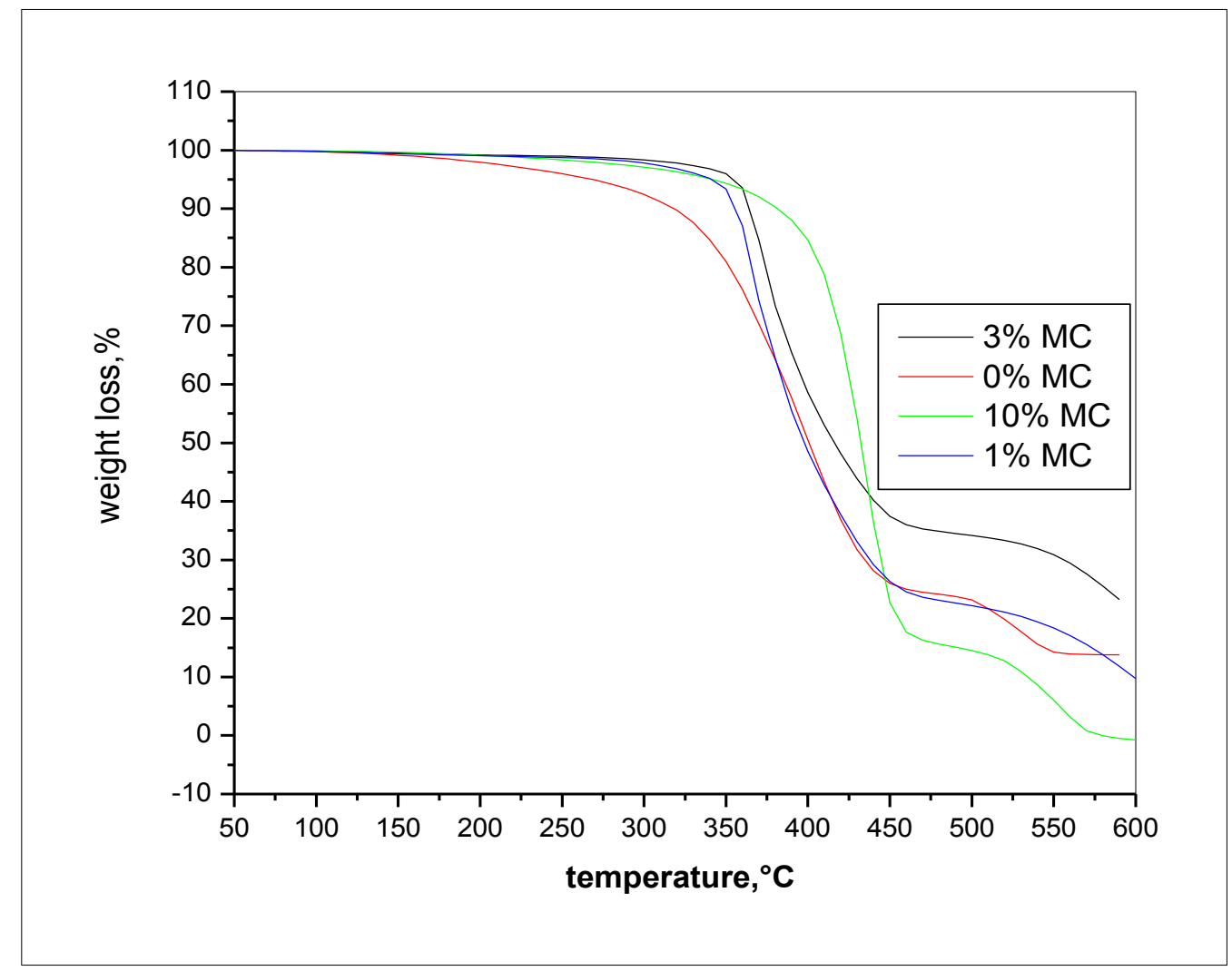

Fig. 2. TGA thermograms of epoxy with MC series.

\subsection{Tensile properties}

Figure 3 shows the effect of clay addition on tensile strength and tensile modulus. The tensile strength of pure epoxy is $61.1 \mathrm{MPa}$. The addition of MC decreases the tensile strength of epoxy material. It is seen from Fig. 3 that addition of clay decreases the strain at break. The low strain value is due to the formation of voids, agglomeration, etc. The effect of MC addition on tensile modulus is seen in Fig. 3. Tensile modulus of pure epoxy is $3 \mathrm{GPa}$. On addition of $\mathrm{MC}$, tensile modulus increases. It is observed that modulus of nanocomposites increases continuously with increasing MC content. An improvement in modulus of $\sim 1.3$ times is observed for the addition of $10 \% \mathrm{MC}$. The orientation of clay platelets and polymer chains with respect to loading direction can also contribute to reinforcement effects. The decreasing rate of modulus at higher clay content $(>2 \% \mathrm{MC})$ is due to presence of unexfoliated aggregates in epoxy polymer matrix. In epoxy/MC composites, there is not much 
improvement in modulus due to the absence of clay distribution at molecular level, and hence does not contribute to molecular strength.

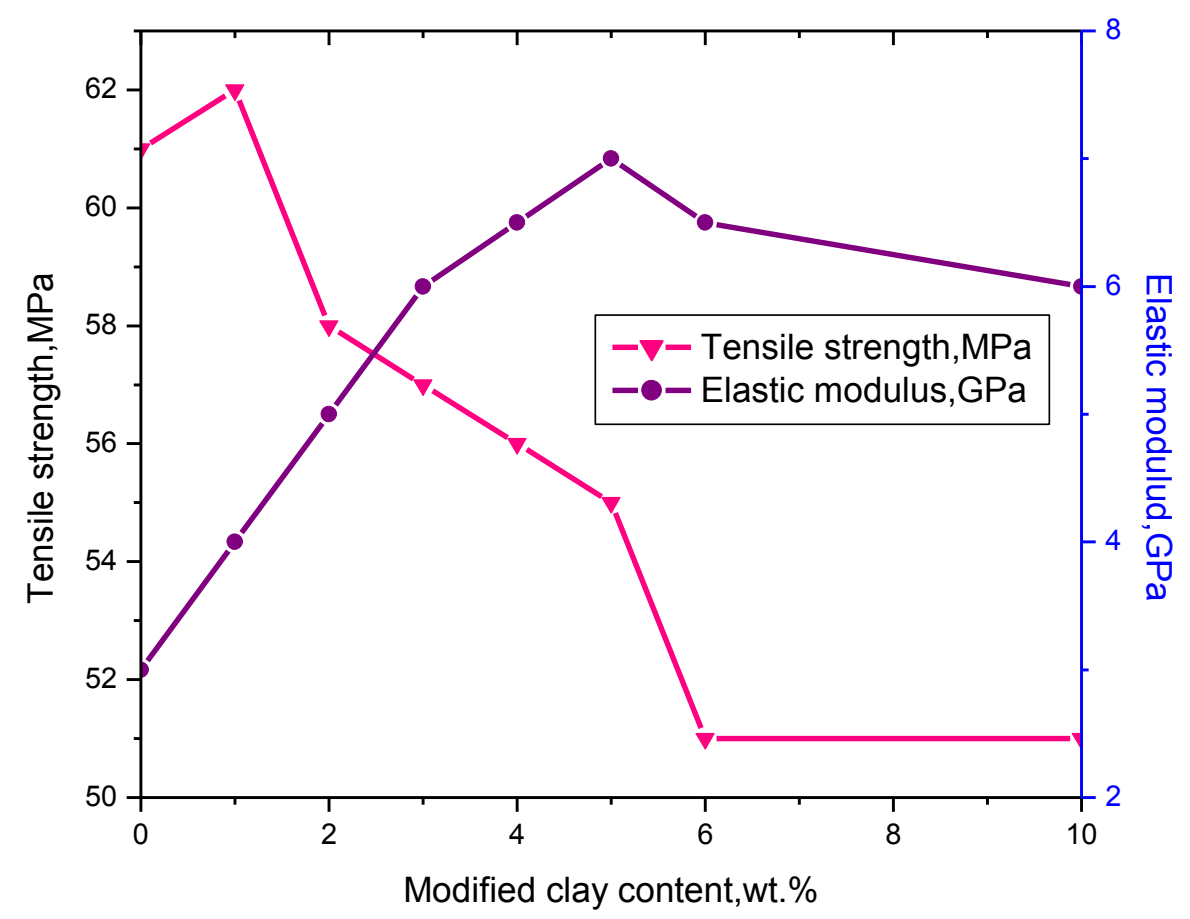

Fig. 3. Effect of clay content on tensile strength and elastic modulus.

The tensile fracture surfaces of epoxy and epoxy filled MC are shown in Fig. 4. If it seen from Fig. 4 that fracture surface of pure epoxy polymer is smooth due to brittle failure. However, on addition of $\mathrm{MC}$ particles, crack surface becomes rough (i.e. ductile nature). The roughness increases as MC content increases in the matrix. The fracture roughness indicates that the resistance of propagation of crack is large and the crack has not propagated as easily as seen in pure epoxy.

The fracture surface roughness indicates that crack propagation is large and increased the torturous path of propagating crack [24]. This effect results in higher stress to failure and caused improved strength of nanocomposites. Though the fracture roughness is predominant at $10 \% \mathrm{MC}$, the existence of unexfolaited aggregates, voids, etc. could have decreased the strength of nanocomposites. Fracture surface of epoxy with $1 \% \mathrm{MC}$ is rougher than pure epoxy. At $3 \% \mathrm{MC}$, the presence of voids is noted.

This indicates that particles have peeled off from material as crack propagates, and create void at the positions where MC particles were there. This also indicates that bonding between matrix and MC particle is poor. For higher clay content $(10 \% \mathrm{MC})$, though the fracture surface is rough, the existence of voids is clearly visible and has decreased the strength of the material.

The poor bonding strength, smooth fracture surface, voids, etc. could decrease the tensile strength of the MC filled epoxy composites. It requires further investigation of the synthetic procedure to understand the methods of improving tensile strength for higher $\mathrm{MC}$ contents. 

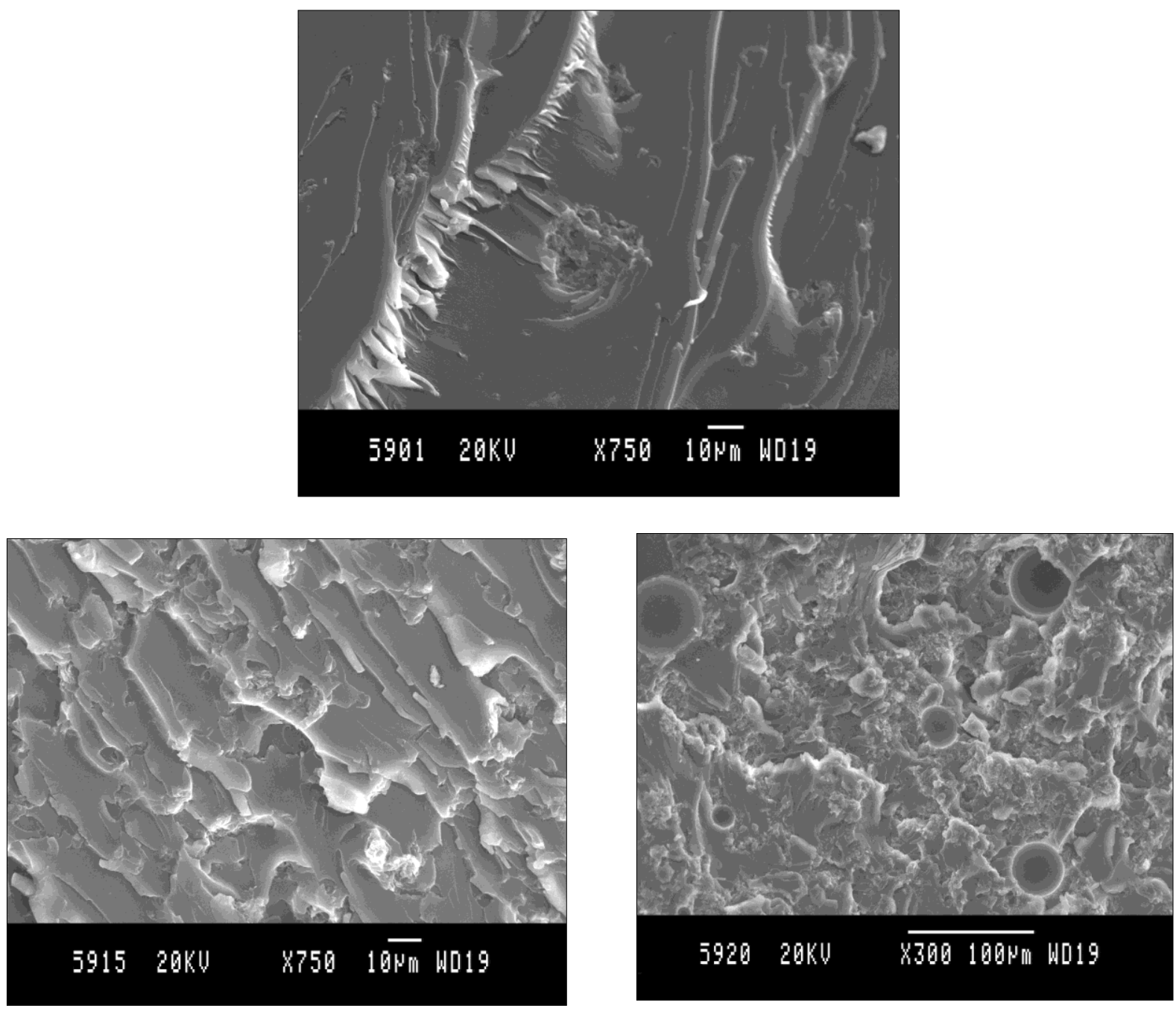

Fig. 4. SEM tensile fracture surface of (a) $E+1 \% M C$, (b) $E+3 \% M C$ and (c) $E+10 \% M C$.

\section{4. Impact properties}

Impact results of MC filled in epoxy polymer is shown in Fig. 5. The addition of MC in epoxy decreases the impact strength of pure epoxy polymer beyond $4 \% \mathrm{MC}$. The decrease in impact strength at higher filler content is due to the existence of agglomeration, unexfoliated aggregates, voids, etc.

The impact fracture surface provides the reason for impact properties in nanocomposites.

The existence of rough surface shows that crack propagation is difficult and could have increased the torturous path and leads to high strength to failure.

This has caused high impact strength of silica nanocomposites up to the addition of 4 wt. \% MC, and on higher addition. Impact results suggest that some additional energy absorbing mechanism is taking place when nano-particles are reinforced in matrix.

Crack pinning, cavitation mechanisms, crack surface roughness, etc. [25] are the possible reasons for high impact strength of MC filled epoxy polymer. 


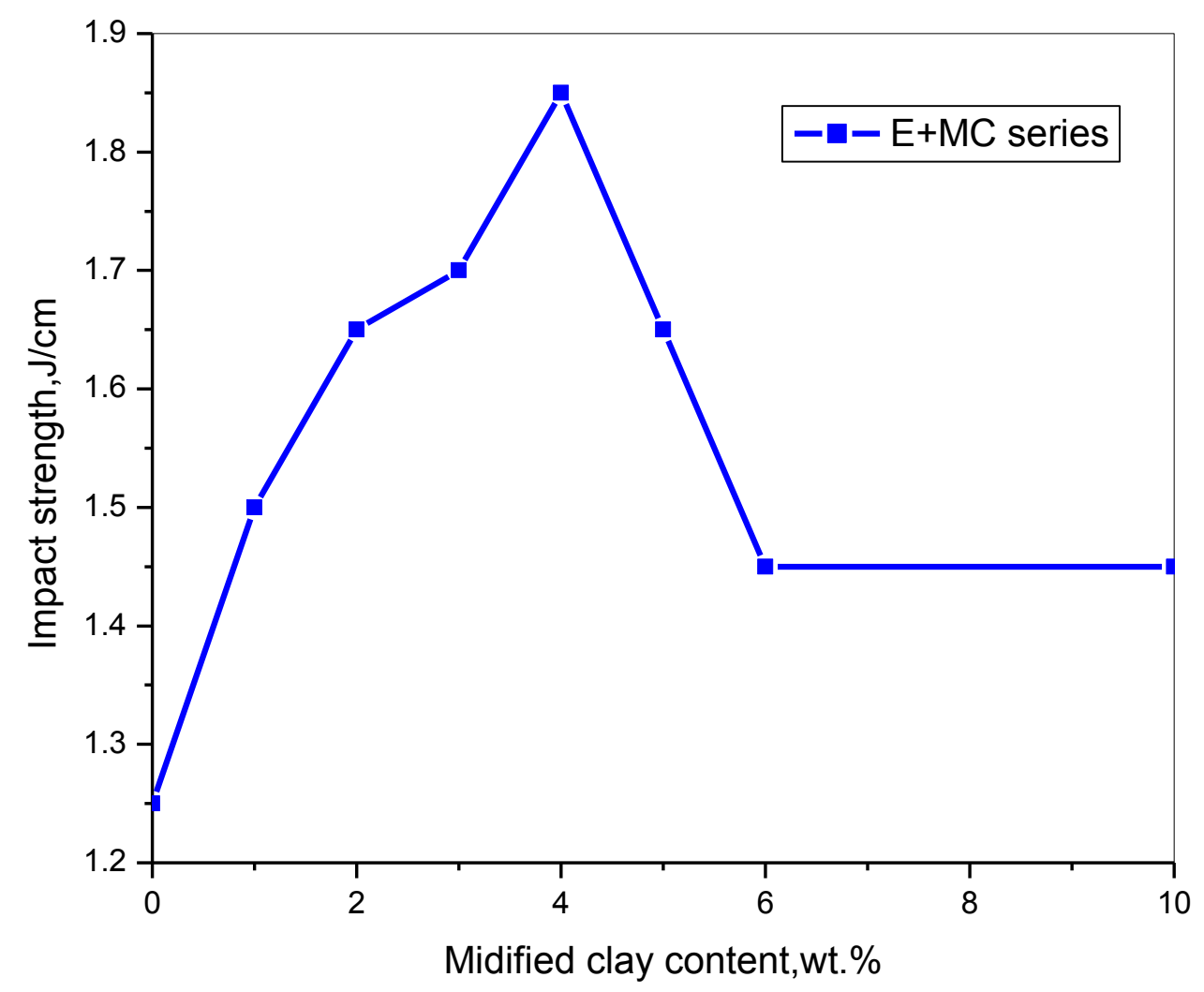

Fig. 5. Impact strength of epoxy filled with MC series.

\section{5. Vibration characteristics}

Table 1 shows the effect of MC addition on natural frequency of epoxy polymer. The $\mathrm{MC}$ addition does not improve the natural frequency of epoxy as is seen in the case of FS filler additions. A negligible effect in stiffness on reinforcement of $\mathrm{MC}$ in epoxy polymer matrix causes such low natural frequencies.

Figure 6 shows the effect of MC addition on damping characteristics of pure epoxy polymer. Damping factors measured by LDM and IHT methods for 1 st and $4^{\text {th }}$ mode of natural frequencies are presented. Damping factors measured for 1 st mode of natural frequencies of epoxy with MC series. It is observed that MC addition increases the damping factors of pure epoxy.

Damping factor measured by IHT shows higher values than that of measured by LDM. The free load during impact causes increased damping in IHT. Since no free load is acting in LDM, and hence damping factor is less than that of IHT.

It is seen that damping factor increases up to $3 \mathrm{wt} . \%$ of $\mathrm{MC}$, and for higher $\mathrm{MC}$ addition in epoxy polymer, damping factor decreases but above the value of matrix material. The increased stiffness due to the addition of MC improves damping factor [24]. Similar effect in damping is noted for 4th mode of natural frequency of epoxy filled MC. Though the addition of MC shows improvement in damping factor. 
Table 1. Frequency dependence of epoxy and epoxy filled MC series.

\begin{tabular}{ccccc}
\hline$(\mathrm{E}+$ wt.\% MC) & $\begin{array}{c}\text { Natural } \\
\text { Frequency at } \\
\text { mode 1, Hz }\end{array}$ & $\begin{array}{c}\text { Natural } \\
\text { Frequency at } \\
\text { mode 2, Hz }\end{array}$ & $\begin{array}{c}\text { Natural } \\
\text { Frequency at } \\
\text { mode 3, Hz }\end{array}$ & $\begin{array}{c}\text { Natural } \\
\text { Frequency at } \\
\text { mode 4, Hz }\end{array}$ \\
\hline E+0 & 17.66 & 117.10 & 194.00 & 297.00 \\
E+1 & 17.23 & 122.07 & 183.75 & 291.5 \\
E+2 & 19.51 & 124.96 & 191.75 & 302.42 \\
E+3 & 20.40 & 135.08 & 204.63 & 295.43 \\
E+5 & 16.20 & 111.04 & 214.06 & 294.26 \\
E+6 & 15.24 & 110.50 & 201.75 & 291.43 \\
E+10 & 15.23 & 110.45 & 201.43 & 291.23 \\
\hline
\end{tabular}

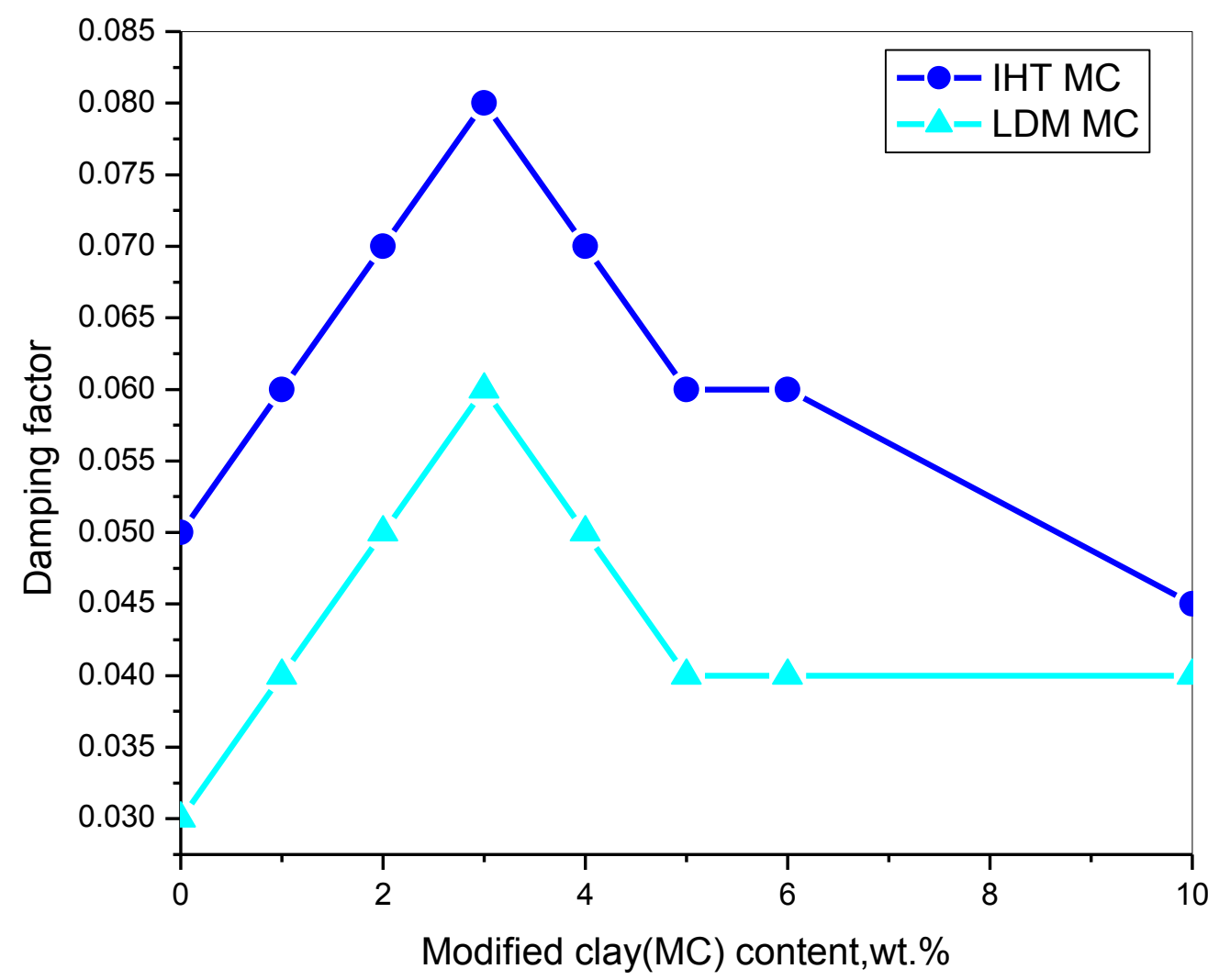

(a)

Fig. 6. Damping factor for epoxy with MC series at (a) $1^{\text {st }}$ mode and (b) 2 nd mode. 


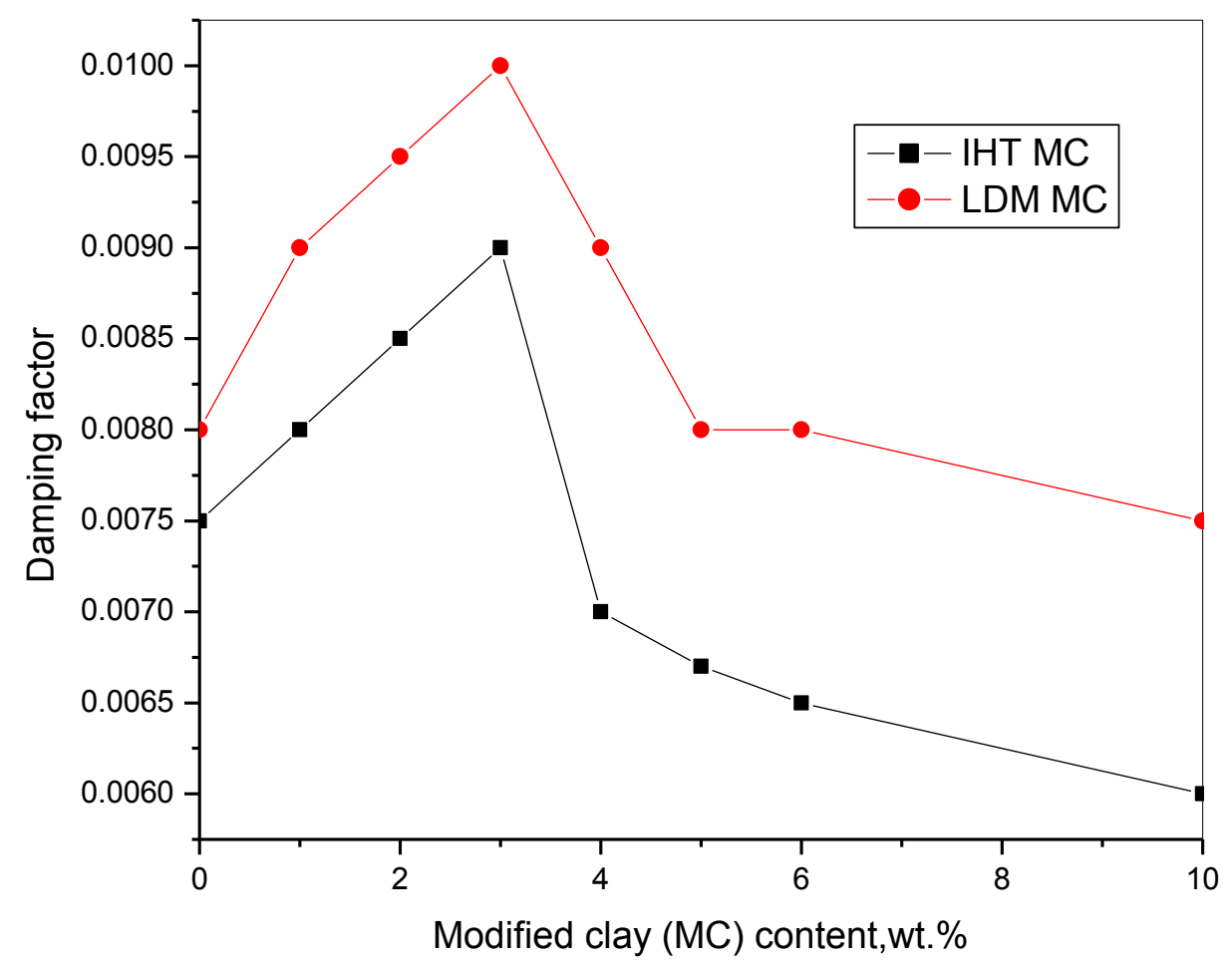

(b)

Fig. 6(continue). Damping factor for epoxy with MC series at (a) $1^{\text {st }}$ mode and (b) 2nd mode.

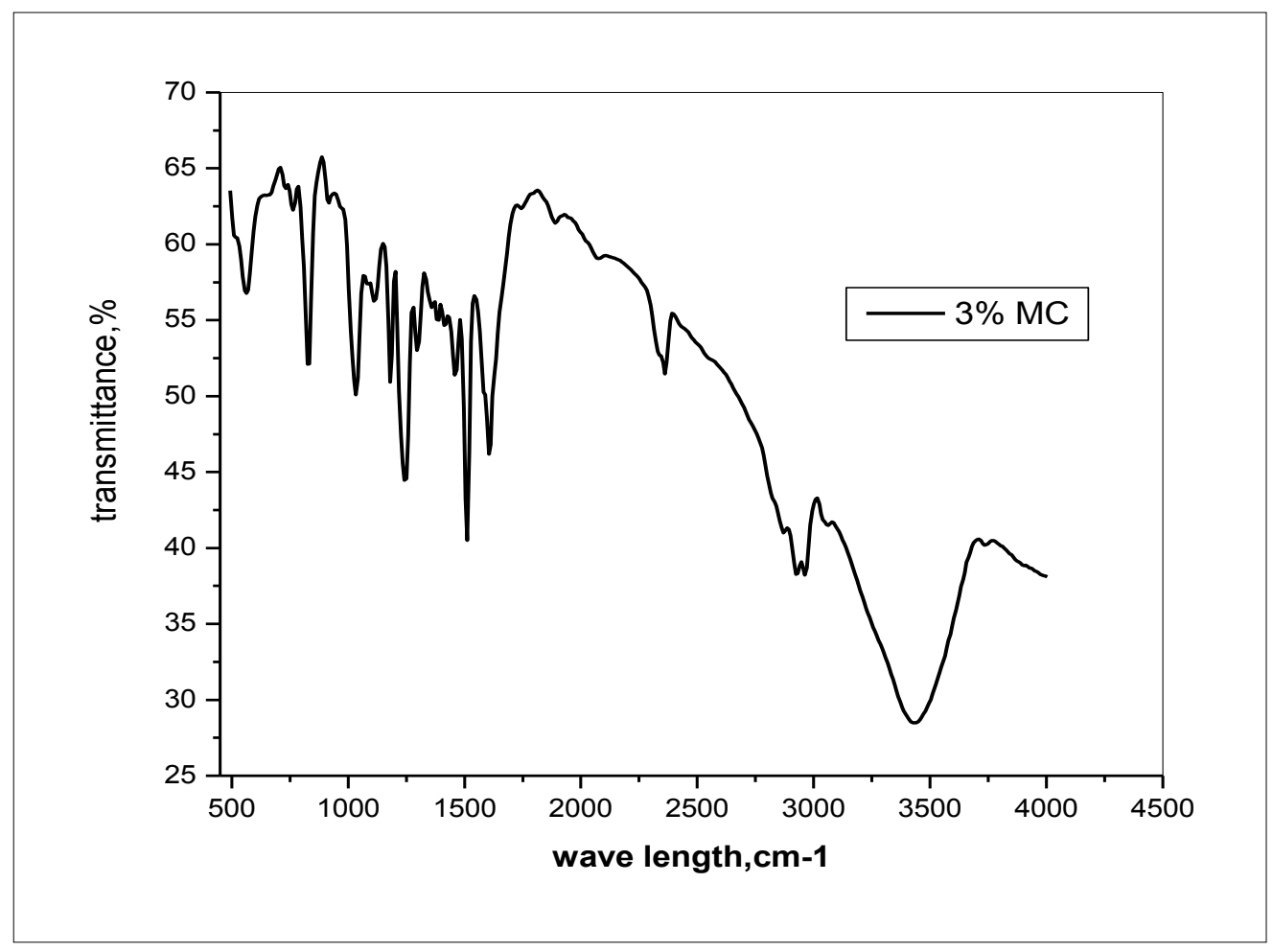

(a)

Fig. 7. FTIR spectra analysis of (a) $E+3 \% \mathrm{MC}$ and (b) $\mathrm{E}+5 \% \mathrm{MC}$. 
From (Fig. 7) the IR spectra of epoxy filled with MC for $3 \mathrm{wt} . \%$ and $5 \mathrm{wt} . \%$ respectively and the characteristic absorption band of the FS is at $1500-1600 \mathrm{~cm}^{-1}$ and the characteristic absorption bands of $\mathrm{C}-\mathrm{H}$ stretching are shown at 2950 and $3000 \mathrm{~cm}^{-1}$.

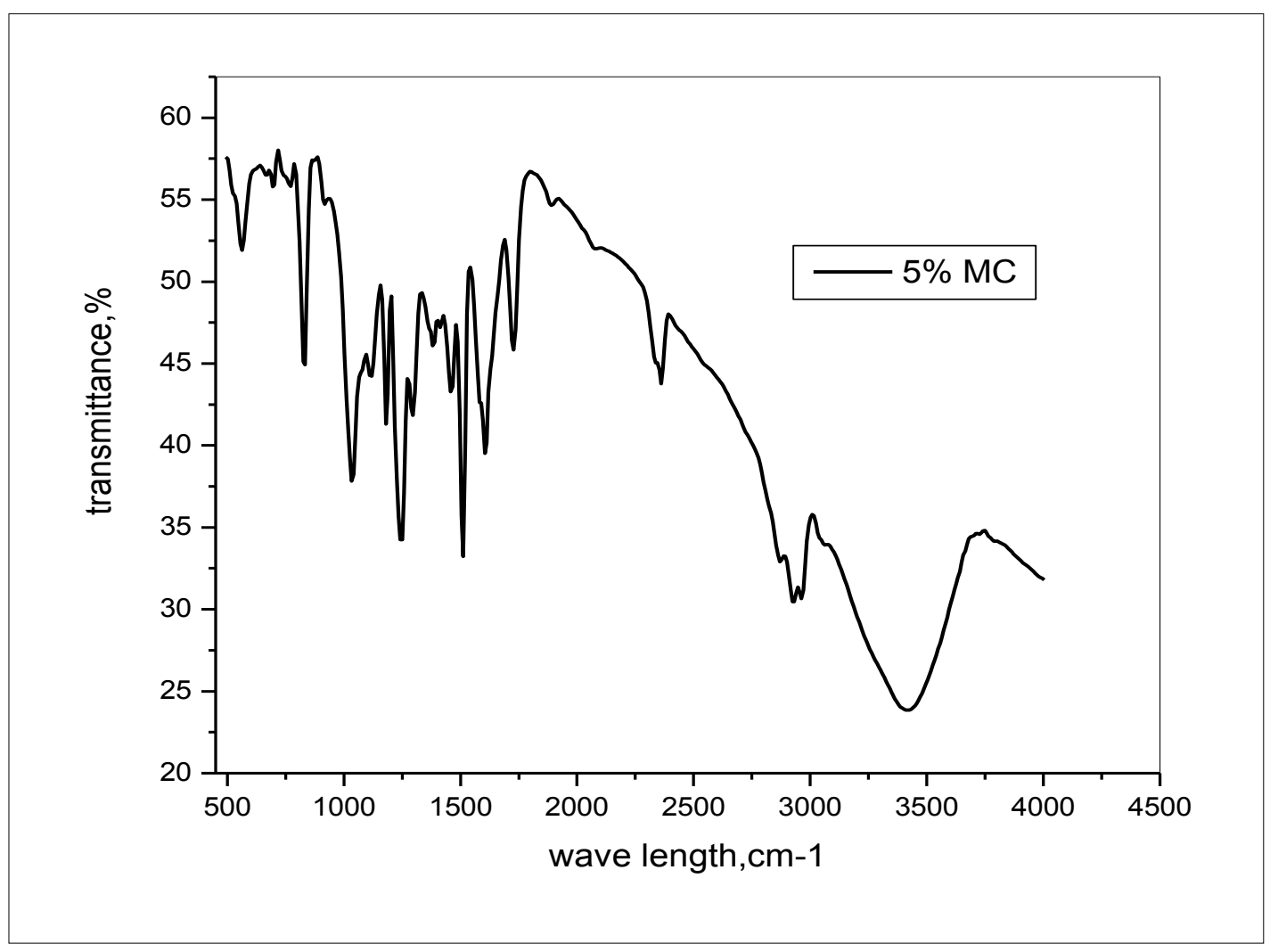

(b)

Fig. 7(continue). FTIR spectra analysis of (a) $\mathrm{E}+3 \% \mathrm{MC}$ and (b) $\mathrm{E}+5 \% \mathrm{MC}$

\section{CONCLUSIONS}

Room temperature cured epoxy polymer filled with modified clay is synthesized by adding TETA curing agent. The MC addition in epoxy matrix does not affect the peak exothermic curing temperature of epoxy resin. Tensile property of nanocomposites shows enhanced tensile modulus than that of pure epoxy resin and epoxy filled MC series. The addition of $\mathrm{MC}$ increases the tensile strength of epoxy polymer and $\mathrm{MC}$ addition decreases the tensile strength of epoxy polymer. Improved impact strength is noted for epoxy filled with MC filled epoxy polymer. Natural frequency of nanocomposites is higher than that of pure epoxy polymer. Damping factor is increased for $3 \mathrm{wt}$. \% epoxy/MC series. 


\section{References}

[1] Ng C. B., Schadler L. S., Siegel R. W., Nano Stuct Mater 12 (1999) 507-510.

[2] Evora V. M. F., Shukla A., Mater Sci Eng A 361 (2003) 358-366.

[3] Zhang M., Singh R. P., Mater Lett. 258 (2004) 408-412.

[4] Wetzel B., Haupert F., Zhang M. Q., Compos Sci. Technol. 63 (2003) 2055-2067.

[5] Wetzel B., Rosso P., Haupert F., Friedrich K., Eng Fract Mech. 73 (2006) 2375-2398.

[6] Adebahr T., Roscher C., Adam J., Eur Coatings J 4 (2001) 144-149.

[7] Lin J. C., Chang L. C., Nien M. H., Ho H. L., Compos Struct. 74(1) (2006) 30-36.

[8] Ragosta G., Abbate M., Musto P., Scarinzi G., Mascia L., Polymer 46 (2005) 10506-10516.

[9] Zheng Y., Zheng Y., Ning R.,. Mater Lett. 57 (2003) 2940-2944.

[10] Moloney A. C., Kausch H. H., Kaiser T., Beer H. R., J Mater Sci. 22 (1987) 381-393.

[11] Bandyopadhyay S., Mater Sci Eng. A 125 (1990) 157-164.

[12] Norman D. A., Robertson R. E., Polymer 44 (2003) 2351-2362.

[13] Fiedler B., Gojny F. H., Wichmann M. H. G., Nolte M. C. M., Schulte K., Comp Sci Technol 66 (2006) 3115-3125.

[14] Johnsen B. B., Kinloch A. J., Mohammed R. D., Taylor A. C., Sprenger S., Polymer 48 (2007) 530-541.

[15] Wichmann M. H. G., Schulte K., Wagner H. D., Comp Sci Technol 68 (2008) 329-331.

[16] Xie X. L., et al., Polym 45 (2004) 6665-6673.

[17] Lazzeri A., Zebarjad S. M., Pracella M., Cavalier K., Rosa R., Polymer 46 (2005) 827-844.

[18] Wichmann M. H. G., Cascione M., Fiedler B., Quaresimin M., Schulte K., Compos Interf 13 (2006) 699-715.

[19] Iyagawa H., Jurek R. J., Mohanty A. K., Misra M., Drzal L. T., Compos A 37 (2006) 54-62.

[20] Qi B., Zhang Q. X., Bannister M., Mai Y. W., Compos Struct 75 (2006)514-519.

[21] Le Pluart L., Duchet J., Sautereau H., Polymer 46 (2005) 12267-12278.

[22] Becker O., Varley R., Simon G., Polymer 43 (2002) 4365-4373.

[23] Juwono A., Edward G., Int. J Nanosci. 4(4) (2005) 501-507.

[24] Mohan T. P., Ramesh Kumar M., Velmurugan R., J Mater Sci 41 (2006) 5915-5925.

[25[ Pinnavaia T. J., Beall G. W., Polymer-clay nanocomposites. Wiley Series in Polymer Science, New York, 2000; 127-148.

[26] Ashok Kumar M., Hemachandra Reddy K., Mohana Reddy Y. V., Intern J Polym Mater 59 (2010) 854-862. 
[27] Ashok Kumar M., Ramachandra Reddy G., Siva Bharathi Y., Venkata Naidu S., Naga Prasad Naidu V., J Comp Mater 46(26) (2010) 3195-3202.

[28] Ashok Kumar M., Hemachandra Reddy K., Ramachandra Reddy G., Venkata Mohana Reddy Y., Subbarami Reddy N., Ind J Macromol 6(2) (2010) (in press).

[29] Ashok Kumar M. , Hemachandra Reddy K., Ramachandra Reddy G., Venkata Mohana Reddy Y., Subbarami Reddy N., Nano Sci Nano Tech 4(2) (2010) (in press).

[30] Ashok Kumar M., Hemachandra Reddy K., Venkata Mohana Reddy Y., Ramachandra Reddy G., Venkatesh Kumar N. S., Nanjunda Reddy B. H., J Metal Mater Sci 52(4) (2010) 305-315.

[31] Ashok Kumar M., Ramachandra Reddy G., Harinatha Reddy G., Hemachandra Reddy K., Venkata Mohana Reddy Y., International Annual Symposium on Advanced Polymeric Materials (APM), CIPET, Chennai, India, March 25-27, 2011 Organized by Advanced research School for technology and product Simulation (ARSTPS). 